\title{
Variations in IL-23 and IL-25 receptor gene structure, sequence and expression associated with the two disease forms of sheep paratuberculosis
}

\author{
Louise Nicol ${ }^{1}$, Anton Gossner ${ }^{1}$, Craig Watkins ${ }^{2}$, Francesca Chianini ${ }^{2}$, Robert Dalziel ${ }^{1}$ and John Hopkins ${ }^{1 *}$
}

\begin{abstract}
The immunopathology of paucibacillary and multibacillary sheep paratuberculosis is characterized by inflammatory $T$ cell and macrophage responses respectively. IL-23 and IL-25 are key to the development of these responses by interaction with their complex receptors, IL-23R/IL-12RB1 and IL-17RA/IL-17RB. In humans, variations in structure, sequence and/or expression of these genes have been implicated in the different pathological forms of tuberculosis and leprosy, and in gastrointestinal inflammatory disorders such as Crohn's disease. Sequencing has identified multiple transcript variants of sheep IL23R, IL12RB1 and IL17RB and a single IL17RA transcript. RT-qPCR assays were developed for all the identified variants and used to compare expression in the ileo-caecal lymph node of sheep with paucibacillary or multibacillary paratuberculosis and uninfected animals. With IL-23 receptor, only the IL I2RB IV 3 variant, which lacks the receptor activation motif was differentially expressed and was significantly increased in multibacillary disease; this may contribute to high Th2 responses. Of the IL17RB variants only full length IL17RB was differentially expressed and was significantly increased in multibacillary pathology; which may also contribute to Th2 polarization. IL17RA expression was significantly increased in paucibacillary disease. The contrast between the IL17RA and IL17RB results may indicate that, in addition to Th1 cells, Th17 T cells are also involved in paucibacillary pathology.
\end{abstract}

\section{Introduction}

Paratuberculosis (Johne's disease) is an endemic enteric disease of ruminants caused by Mycobacterium avium subspecies paratuberculosis (MAP) [1]; and like human mycobacterial infections, clinical paratuberculosis develops in a minority of infected animals [2]. In sheep, approximately one-third of the diseased animals develop paucibacillary or tuberculoid pathology and two-thirds develop multibacillary or lepromatous disease [2]; with lesions localized largely in the lamina propria of the terminal ileum [2]. Paucibacillary pathology is characterized by lymphocyte infiltration, granulomatous inflammation and few bacteria. In contrast multibacillary lesions are

\footnotetext{
*Correspondence: john.hopkins@ed.ac.uk

${ }^{1}$ The Roslin Institute and R(D)SVS, University of Edinburgh, Easter Bush, Midlothian EH25 9RG, UK

Full list of author information is available at the end of the article
}

composed largely of heavily infected macrophages [2]. There is progression from sub-clinically infected to paucibacillary disease and terminal multibacillary pathology [3]; however progression occurs less frequently in sheep than in cattle and paucibacillary disease is usually fatal in infected sheep $[2,4,5]$.

The immunology of paratuberculosis in sheep is also similar to tuberculoid and lepromatous forms of the human mycobacterial diseases, tuberculosis and leprosy $[6,7]$. Paucibacillary disease is associated with a highly polarized Th1/Th17 response, characterized by high levels of IL-12, IL-17A and IFN $\gamma$ [8-10]; and multibacillary paratuberculosis is linked with a strong Th2 response with high levels of IL-5 and IL-10 [8-11]. MAP has also been implicated as an aetiological agent of inflammatory intestinal diseases in humans because of the apparent similarity between the pathology of paucibacillary paratuberculosis and Crohn's disease [12]. Like the human 
mycobacterial diseases, the epidemiology of paratuberculosis strongly suggests a host genetic susceptibility to disease severity and pathological form [13, 14]. Many of the genes associated with severity of human disease and pathology belong to the pathways that control differential $\mathrm{T}$ cell activation [13]; and genes in these pathways are also linked to gastrointestinal inflammatory diseases including ulcerative colitis and Crohn's disease [12-15].

Of particular interest in this study are genes for the cytokines and cytokine receptors that control the expression of Th1, Th17 and Th2 subsets associated with the different forms of chronic gastrointestinal inflammation [15, 16] and are also important in the pathogenesis of tuberculosis and leprosy [7-13]. The activation of Th1/Th17 T cells is regulated by the interaction of the related heterodimeric cytokines IL-12 and IL-23 with their respective receptor complexes, IL-12RB1/IL-12RB2 and IL-12RB1/ IL-23R [17]. Macrophages play a critical role in the presentation of antigen to $\mathrm{T}$ cells and their downstream activation and polarization, and are the target cells for MAP infection [18]. Mycobacterial infection of macrophages affects the expression of IL-12 and IL-23 [8, 19, 20] and therefore potentially influences the polarization of the immune response and consequently disease pathology. In contrast, the activation of Th $2 \mathrm{~T}$ cells is influenced by IL-25 [21], which is produced by cells such as intestinal epithelium and innate lymphoid cells 2 (ILC2) and functions by interacting with its complex receptor IL-17RA/ IL-17RB on T cells [22].

Variations in gene structure, sequence or expression levels of these cytokines and their receptors have been implicated in human mycobacterial pathogenesis and/ or gastrointestinal and respiratory inflammatory diseases $[13,23]$. Genome wide association studies have identified the association of single nucleotide polymorphisms (SNPs) of IL12B and IL23R with susceptibility to leprosy and tuberculosis $[13,24]$ and with Crohn's disease [16]. In addition, specific splice variants of $I L 12 B$ and IL23R have been linked to disseminated BCG infection [25] and with inflammatory bowel disease [26]. Studies on IL-25 and its receptor complex have found similar associations with inflammation; SNP analysis of IL17RA has linked three alleles associated with aspirin exacerbated respiratory disease [27] and IL17RB polymorphisms with asthma [28].

The aims of this study were to characterize the different sequence and transcript variants of the sheep IL-23 and IL-25 receptor complexes associated with Th1/Th17 and Th2 $\mathrm{T}$ cell polarization within the ileo-caecal lymph node (ICLN), the major immune inductive site for pathogens infecting the terminal ileum [29]; and to assess the expression of the different transcript variants in relation to defined paucibacillary and multibacillary pathology of sheep paratuberculosis.

\section{Materials and methods}

\section{Animals, disease diagnosis and tissue collection}

Animals with clinical paratuberculosis were out-bred Blackface or Blackface cross female sheep with naturally acquired MAP infection sourced from six farms; uninfected controls were from a single source with no history of paratuberculosis. The pathology of paratuberculosis was confirmed in clinically-affected sheep at postmortem, by haematoxylin and eosin and Ziehl-Neelsen histopathology of the terminal ileum, MLN and ICLN. Infection was confirmed in affected sheep by $I S 900$ PCR; all control sheep were IS900 negative (Table 1). There were six animals in each of three groups. Tissue was ICLN, removed immediately post-mortem, cut into blocks of $\sim 0.5 \mathrm{~g}$ and placed in five volumes of RNAlater (Ambion, Huntingdon, UK), which were then incubated overnight at $4{ }^{\circ} \mathrm{C}$ and stored at $-80^{\circ} \mathrm{C}$. No animals were euthanized specifically for this study; the animals were humanely culled for clinical reasons of paratuberculosis disease or for reasons unrelated to this study (uninfected controls).

\section{IS900 quantitative PCR}

ICLN of all animals was tested for the presence of MAP by PCR for insertion sequence IS900. Two independent primer sets were used [30,31]; set 1 generated an amplicon of 99 bp (for: GTTCGGGGCCGTCGCTTAGG; rev: GCGGGCGGCCAATCTCCTT) and set 2 generated a product of $314 \mathrm{bp}$ (for: CTGGCTACCAAACTC CCGA; rev: GAACTCAGCGCCCAGGAT). Genomic DNA (gDNA) was purified using the Wizard ${ }^{\circledR}$ Genomic DNA Purification Kit (Promega, UK). All reactions used FastStart Taq DNA Polymerase (Roche Diagnostics, UK) following the manufacturer's instructions, with $500 \mathrm{ng}$ of gDNA and $0.2 \mu \mathrm{M}$ of each primer. PCRs were performed using a Veriti ${ }^{\circledR}$ Thermal Cycler (Applied Biosystems) with four separate reactions performed for each primer set at different annealing temperatures. PCR reactions consisted of a heat activation step for $5 \mathrm{~min}$ at $95{ }^{\circ} \mathrm{C}, 35$ cycles of $15 \mathrm{~s}$ at $95^{\circ} \mathrm{C}, 15 \mathrm{~s}$ at $55,58,60$ and $62{ }^{\circ} \mathrm{C}$, and $30 \mathrm{~s}$ at $72{ }^{\circ} \mathrm{C}$, with a final elongation step of $10 \mathrm{~min}$ at $72{ }^{\circ} \mathrm{C}$.

PCR products were analysed on a $2 \%$ agarose gel electrophoresis, purified with a MinElute Gel Extraction Kit (Qiagen, UK) according to the manufacturer's instructions; cloned using a TOPO TA cloning kit for sequencing (Invitrogen) and sequenced using BigDye Terminator v3.1 Cycle Sequencing Kit and 3730 DNA Analyser (Applied Biosystems). The presence of an amplicon, confirmed by sequencing, from either primer set was taken as a positive result for the presence of MAP; the absence of an amplicon in all PCR reactions was confirmation of absence of MAP infection. All multibacillary 
Table 1 Breed, age, histopathology and disease diagnosis of sheep

\begin{tabular}{|c|c|c|c|c|c|c|c|c|}
\hline Sheep ID & Breed & Origin $^{a}$ & Age (years) & SGI & $\mathrm{AFB}^{\mathrm{C}}$ & Tissue specific lesion grade ${ }^{d}$ & $I S 900^{\mathrm{e}}$ & Diagnosis $^{f}$ \\
\hline SH.139 & Blackface & A & 3 & 5 & 4 & Severe &,++ & Multibacillary \\
\hline SH.140 & Blackface & A & 3 & 7 & 4 & Severe &,++ & Multibacillary \\
\hline SH.146 & Blackface $x$ & $B$ & 2.5 & 5 & 4 & Severe &,++ & Multibacillary \\
\hline SH.190 & Blackface & C & 3 & 5 & 4 & Severe &,++ & Multibacillary \\
\hline SH.199 & Blackface & C & 2 & 6 & 4 & Severe &,++ & Multibacillary \\
\hline SH.204 & Blackface & D & 1.5 & 6 & 4 & Severe &,++ & Multibacillary \\
\hline SH.107 & Blackface x & $E$ & 2.5 & 2.5 & 0 & Mild &,++ & Paucibacillary \\
\hline SH.147 & Blackface x & B & 2 & 3 & 0 & Mild &,++ & Paucibacillary \\
\hline SH.155 & Blackface & $\mathrm{F}$ & 3 & 2 & 0 & Mild &,++ & Paucibacillary \\
\hline SH.160 & Blackface x & B & 3 & 2.5 & 0 & Mild &,++ & Paucibacillary \\
\hline SH.188 & Blackface x & $B$ & 4 & 4 & 1 & Moderate &,++ & Paucibacillary \\
\hline SH.205 & Blackface & D & 4 & 2 & 0 & Mild &,++ & Paucibacillary \\
\hline K207 & Blackface & G & 2.5 & 0 & 0 & ND &,-- & Control \\
\hline K208 & Blackface & G & 2.5 & 0 & 0 & ND &,-- & Control \\
\hline K213 & Blackface & G & 2.5 & 0 & 0 & ND &,-- & Control \\
\hline $\mathrm{K} 224$ & Blackface & G & 2.5 & 0 & 0 & ND &,-- & Control \\
\hline K227 & Blackface & G & 2.5 & 0 & 0 & ND &,-- & Control \\
\hline K229 & Blackface & G & 2.5 & 0 & 0 & ND &,-- & Control \\
\hline
\end{tabular}

a Source farms.

b Severity of granulomatous inflammation (SGI) grading: based on total number of epithelioid macrophages and leukocyte distribution patterns of the terminal ileum [5].

c Acid fast bacteria (AFB) -; grading: grades 0-2 were defined as paucibacillary; grades 3-4 were defined as multibacillary observed in terminal ileum tissue [5].

d Tissue specific lesion grading: for each terminal ileum histological section, the sum of the points (SGI + AFB) was used to determine tissue-specific lesion grades. A severity of "none" was assigned to those with a lesion grade of 0 , "mild" was assigned to a lesion grade of $\geq 2$ and $\leq 3$, "moderate" was assigned to those with a lesion grade of $>3$ and $\leq 5$ and "severe" was assigned to a lesion grade of $6-11$.

e IS900 PCR result using each of the two primer sets.

f Diagnosis: based on histopathological observations.

and paucibacillary animals were positive and all uninfected, control animals were negative for IS900.

\section{Cloning of ovine gene fragments}

RNA was isolated from $\sim 20 \mathrm{mg}$ of ICLN using the Ribopure Kit (Ambion, UK) according to the manufacturers' instructions. Genomic DNA was removed by On-column PureLink ${ }^{\circledR}$ DNase I treatment (Ambion). RNA quantity, quality and integrity were determined using a Labtech NanoDrop ND-1000 spectrophotometer and Agilent 2200 TapeStation system; samples had an RNA Integrity Number of 7.4-9. cDNA was synthesised from 1.0 $\mu \mathrm{g}$ RNA using SuperScript ${ }^{\mathrm{TM}}$ II RT with RNaseOUT (Invitrogen, UK) and oligo-dT(15) primer (Promega, UK), in $20 \mu \mathrm{L}$ final volume. The predicted sequences of the sheep genes were obtained by NCBIBLAST of the bovine (or if bovine sequences were not available, human and/or mouse) sequences against the Oar v3.1 sheep genome assembly [32]. Primers were selected using Primer-BLAST [33] and reanalysed using Net Primer [34]. The primers were used to amplify overlapping sections of genes, with at least 100 bp overlap of amplicons; each primer set was used in RT-PCR using FastStart Taq (Roche, UK) as per manufacturer's instructions. New primers were selected (Additional file 1) from these assembled sequences to obtain full length transcripts using Platinum ${ }^{\circledR}$ Taq DNA Polymerase High Fidelity (Invitrogen). PCR products were purified using a MinElute PCR Purification Kit (Qiagen), ligated into pGEM ${ }^{\circledR}-\mathrm{T}$ Easy Vector (Promega). Plasmids were extracted using QIAprep Spin MiniPrep Kit (Qiagen) following the manufacturers' protocol. At least three clones from all diseased sheep, for each insert, were sequenced using T7 and SP6 primers, with BigDye ${ }^{\circledR}$ Terminator v3.1 Cycle Sequencing Kit (Applied Biosystems, UK). The GeneRacer $^{\mathrm{TM}}$ Kit for full-length, RNA ligase-mediated rapid amplification of $5^{\prime}$ and $3^{\prime}$ cDNA ends (Invitrogen) was used to sequence the $5^{\prime}$ and $3^{\prime}$ untranslated region (UTR).

\section{Quantitative real-time RT-PCR analysis}

Primers for quantitative real-time RT-PCR (RT-qPCR) were selected and optimized for all genes and variants (Additional file 2). Primers were designed overlapping 
exon/exon boundaries to ensure specificity for variants; these were amplified and sequenced using end-point RTPCR to ensure specificity before performing RT-qPCR. Reactions contained $2 \mu \mathrm{L}$ template cDNA (diluted 1/101/40), $7.5 \mu \mathrm{L}$ FastStart Universal SYBR Green Master (Rox) $2 \times$ concentration (Roche, UK), $0.2-1.0 \mu \mathrm{L}$ of each primer at $10 \mathrm{mM}$ and nuclease-free water to $15 \mu \mathrm{L}$. All reactions were prepared using a CAS $-1200^{\mathrm{TM}}$ Precision Liquid Handling System and performed on the RotorGene $^{\mathrm{TM}} 3000$ or Rotor-Gene Q (Qiagen). The amplification profile used was the same for each gene except for the annealing temperature; $5 \mathrm{~min}$ at $94{ }^{\circ} \mathrm{C}$, followed by 40 cycles of $20 \mathrm{~s}$ at $94{ }^{\circ} \mathrm{C}, 20 \mathrm{~s}$ at optimized annealing temperature for each primer set (Additional file 2) and $20 \mathrm{~s}$ at $72{ }^{\circ} \mathrm{C}$, followed by dissociation curve analysis to confirm a single gene product; amplicons were sequenced to confirm primer specificity. Relative expression levels were quantified in duplicate in three separate RT-qPCR runs, each time using cDNA from a different $\mathrm{RT}$ reaction, a notemplate control was included in all runs. Linearity and efficiency of PCR amplification was determined for each primer pair using a standard curve generated by a dilution series of a pool of sample cDNA. All reactions had an efficiency of $>90 \%$ and correlation coefficients were $R^{2}>0.98$ and a single peak melt curve.

Relative gene expression levels were calculated in GenEx 5 Standard Programme (MultiD Analyses AB, Sweden) using the comparative $2-(\Delta \Delta \mathrm{Cq})$ method and normalized to the geometric mean of YWHAZ and $S D H A$. Fold changes were calculated from $\triangle \mathrm{Cq}$ values using GenEx. The expression level in the three groups for each variant was analysed by one-way ANOVA; the difference between group means for each variant were analysed using Tukey's multiple comparison test within one-way ANOVA, with a significance threshold of $p \leq 0.05$.

\section{Results}

Cloning and sequencing identified six transcript variants of $I L 23 R$, five variants of $I L 12 R B 1$, a single IL17RA transcript and four $I L 17 R B$ variants (Table 2).

\section{Characterization of sheep IL23R and IL12RB1}

Sheep $I L 23 R$ is encoded by 11 exons on the plus strand of chromosome 1 (NC_019458.1) and encodes a mature protein of 627 amino acids. IL23Rv1 has a 29 bp insertion in the 5' UTR (Chr1: 42464 555-42 464 584) but has an identical predicted protein sequence to full length IL-23R (Additional file 3). IL23Rv2 has a 21 bp deletion (530-551) in exon 4 (Chr1: 42476 073-42 476 094) that results in the loss of 7 amino acids (YVVYVKS) at amino acid positions 158-164 (151-157 in IL-23Rv2), and a 2 bp insertion that causes a frame shift and a premature
Table 2 Genbank accession numbers for the nucleotide and protein sequences of sheep IL12RB1, IL17RA, IL17RB and IL23R

\begin{tabular}{|c|c|c|}
\hline Gene & Nucleotide_id & Protein_id \\
\hline IL23R & LN868336 & CRX77112.1 \\
\hline IL23Rv1 & LN868337 & CRX77113.1 \\
\hline IL23Rv2 & LN868338 & CRX77114.1 \\
\hline IL23Rv3 & LN868339 & CRX77115.1 \\
\hline IL23Rv4 & LN868340 & CRX77116.1 \\
\hline IL23Rv5 & LN868341 & CRX77117.1 \\
\hline $\mid L 12 R B 1$ & LN878970 & CUH82712.1 \\
\hline IL $12 R B 1 v 1$ & LN878971 & CUH82713.1 \\
\hline IL 12RB1V2 & LN878972 & CUH82714.1 \\
\hline IL12RB1V3 & LN878973 & CUH82715.1 \\
\hline IL12RB1V4 & LN878974 & CUH82716.1 \\
\hline IL 17RA & LN878979 & CUH82721.1 \\
\hline$I L 17 R B$ & LN878975 & CUH82717.1 \\
\hline $\mid L 17 R B V 1$ & LN878976 & CUH82718.1 \\
\hline IL17RBV2 & LN878977 & CUH82719.1 \\
\hline IL 17RBV3 & LN878978 & CUH82720.1 \\
\hline
\end{tabular}

stop codon resulting in a protein of 287 amino acids (Additional file 3). IL23Rv3 has a 28 bp insertion (878906) in exon 6 (Chr1: 42492 950-42 492 977) and is predicted to encode a truncated protein of 268 amino acids. IL23Rv4 does not contain exon 8 (Chr1: 42512 41742512506 ) and encodes a 597 amino acid protein as a consequence of a 30 amino acid deletion (VPQVTMKSFQHDTQNSGLLIASIFKKHLTS); this causes the excision of the extracellular region. IL23v5 has a deletion of exon 9 (Chr1: 42515 314-42 515419 ) and is predicted to encode a truncated protein of 356 amino acids.

Sheep IL12RB1 is encoded by 16 exons on the plus strand of chromosome 5 (NC_019462.1) and is predicted to encode a protein of 730 amino acids. The $5^{\prime}$ UTR is at the $5^{\prime}$ end of exon 1 , the extracellular region spans exons $1-13$, the transmembrane region is encoded by exon 14 and the $3^{\prime}$ UTR is located at the $3^{\prime}$ end of exon 16. IL12RB1v1 contains a deletion from the $3^{\prime}$ end of exon 5 to exon 8 (Chr5: 4857 176-4 859 356), which leads to a frame shift and a truncated protein of 185 amino acids. IL12RB1v2 contains a 651 bp deletion spanning the $3^{\prime}$ end of exon 1 to the $5^{\prime}$ end of exon 7 (Chr5: 4853 183-4 858 549); this results in a 217 amino acid deletion at position 16-233 in the extracellular region. IL12RB1v3 contains a 528 bp deletion from exon 3 to exon 7 (Chr5: 4855 325-4 858 535) that causes a 176 amino acid deletion at position 51-226 within the extracellular region (Additional file 3). IL12RB1v4 contains a deletion from the $3^{\prime}$ end of exon 4 to the $5^{\prime}$ end of exon 9 (Chr5: 4855 845-4 860 357) causing a frame shift and 
a truncated protein of 163 amino acids. All four IL12RB1 splice variants are predicted to encode proteins containing the extracellular domain only.

\section{Characterization of sheep IL17RA and IL17RB}

Only one sheep IL17RA transcript was identified (Table 1). This is a partial sequence; the $5^{\prime} 1306 \mathrm{bp}$ mapped to chromosome 3 of Oar v3.1 (NC_019460.1) with $>99 \%$ identity; however the $3^{\prime} 581$ bp did not map, as this region of Oar v3.1 genome assembly is incomplete. Comparison with human IL17RA transcript variants 1 and 2 (NM_014339.6 and NM_001289905.1) shows that the sheep gene is orthologous to human variant 1 as it contains the region encoded in humans by exon 11 (Chr3: 212818 526-212 818 627). The RT-qPCR primers used to quantify sheep IL17RA transcript expression were situated in exons 4 and 5 .

Sheep ILITRB is encoded by 11 exons on the minus strand of chromosome 19 (NC_019476.1) and is predicted to encode a mature protein of 497 amino acids. The splice variant $I L 17 R B v 1$ has a deletion of 96 bp (9751071) that results in a 32 amino acid deletion at position 311 causing a truncated intracellular domain and the loss of the conserved TRAF6 binding motif. IL17RBv2 has a complete deletion of exon 4 (Chr19: 47056 66747054 190) that causes a frame shift and a predicted protein of only 96 amino acids. IL17RBv3 has a deletion of exon 4 and a $177 \mathrm{bp}$ insertion (651-828) at the $5^{\prime}$ end of exon 8 (Chr19: 47050 145-47 049 971); this also results in a premature stop codon and a predicted protein of 96 amino acids.

\section{Quantification of receptor expression}

RT-qPCR assays were developed and expression levels of the four cytokine receptor transcripts were quantified in the paucibacillary, multibacillary and uninfected, control animals. However only IL23R, IL12RB1 and IL12RB1v3 and $v 4, I L 17 R A, I L 17 R B$ and $I L 17 R B v 2$ and $v 3$ could be accurately quantified; expression levels of all the others were too low for accurate measurement. Positive control assays, using a template sample known to contain the individual variants were used to confirm the reliability of the assay.

Of the IL23R and IL12RB1 variants only IL12RB1v3 showed evidence of differential expression (Figure 1) with a significant 2.1 -fold $(p=0.04)$ increase in expression in the multibacillary sheep in comparison to paucibacillary animals. Of the receptors for IL-25 (Figure 2), IL17RA was significantly higher (Table 3 ) in paucibacillary sheep when compared to both multibacillary (2.0-fold, $p=0.001)$ and control sheep (2.2-fold, $p=0.02$ ). Full length $I L 17 R B$ was significantly higher in the multibacillary versus control comparison (2.49-fold, $p=0.04$ ) but

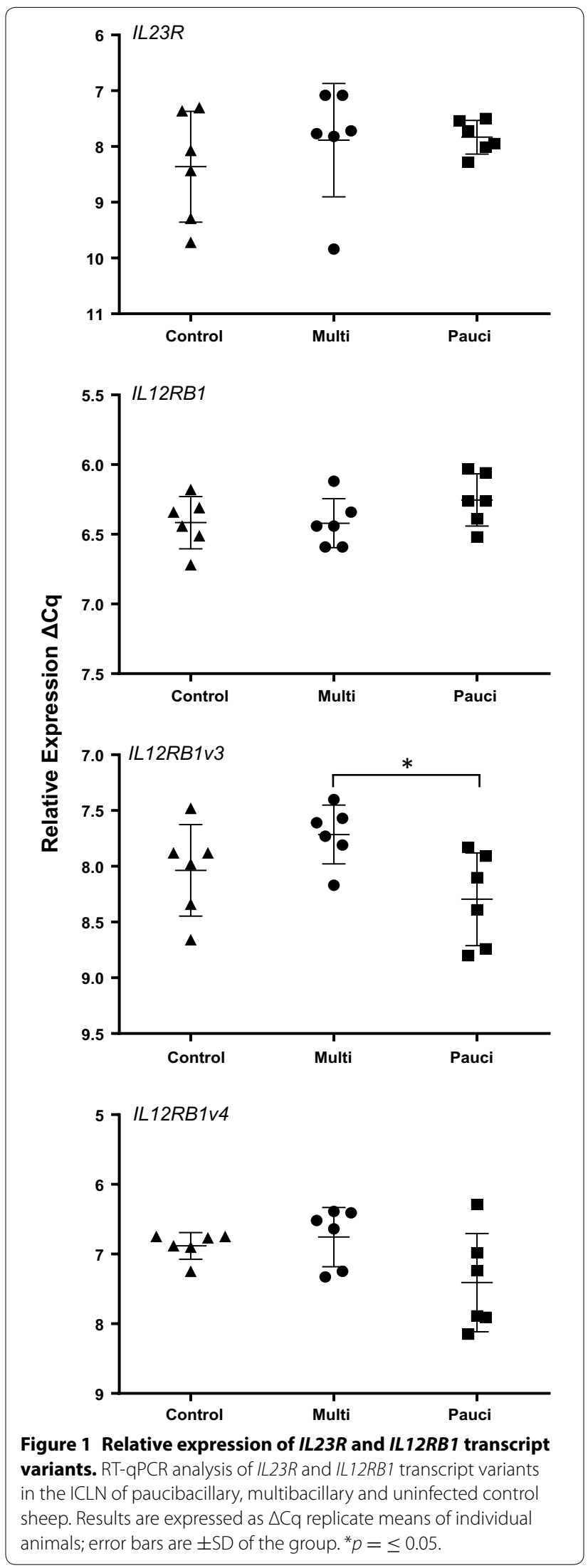




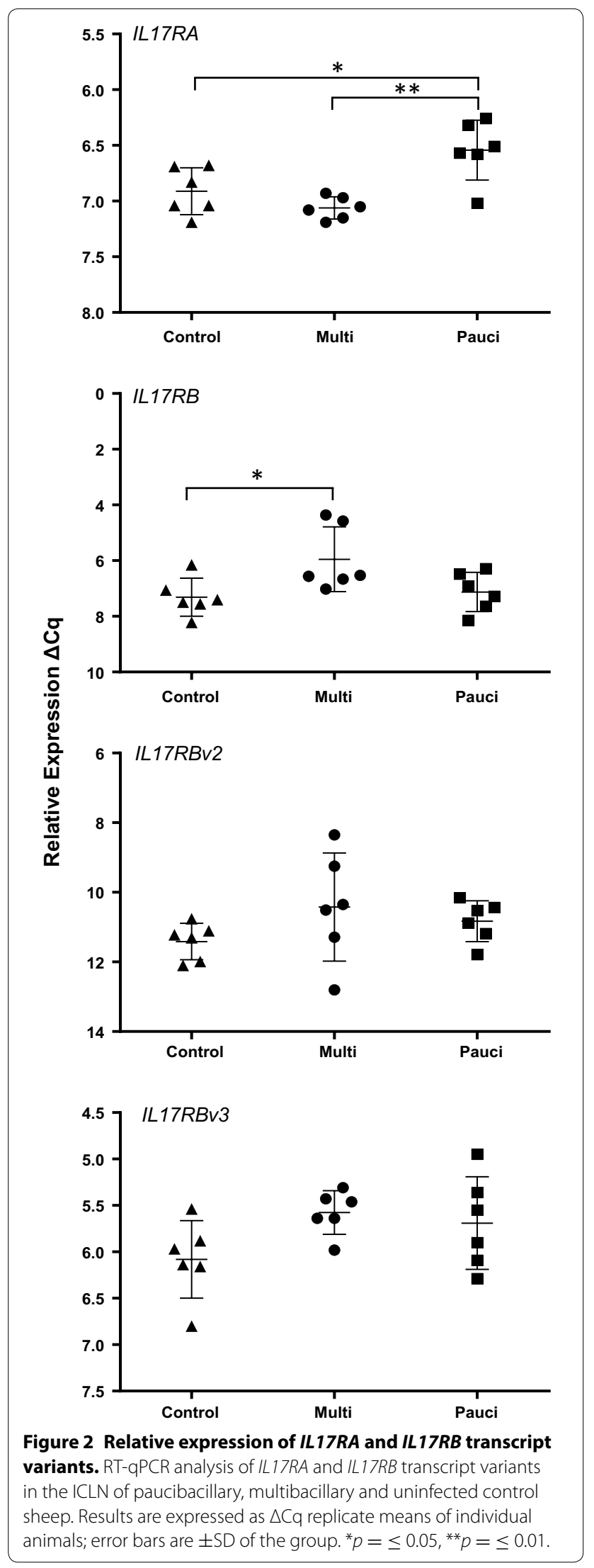

not in the other comparisons (although it was 2.08-fold higher in the multibacillary vs. paucibacillary comparison, but $p=0.08$ ). No significant differential expression was seen with $I L 17 R B v 2$ or $v 3$.

\section{Discussion}

This study is the first investigation into structural, sequence and quantitative variation of expression of genes of the IL-23 and IL-25 receptor complexes, in relation to the different pathological forms of sheep paratuberculosis. Sequencing cDNA from the ICLN of paratuberculosis-diseased sheep identified multiple transcript variants of all genes except IL17RA.

Splice variation is a common feature of these genes in many species including humans. Ensembl 82 [35] reports four transcript variants and three protein-coding isoforms of human IL23R (ENSG00000162594). However up to 24 human isoforms have been identified [36] and similar patterns can be recognised in the sheep and human variants, with four sheep variants (IL23Rv2-v5) predicted to encode truncated proteins. IL23Rv2, $v 3$ and $v 5$ lack the transmembrane and intracellular domains and are likely not to encode cell receptors but to act as antagonists as has been described for human $I L 23 R$ variants [36]. IL23Rv5 specifically lacks exon 10 (exon 9 in human IL23R) and is therefore equivalent to human IL23R 4 9, which is strongly linked to human IBD [26]. IL23Rv4 encodes a protein with a truncated extracellular domain, although as with all the variants $I L 23 R v 4$ retains the conserved WSXWS class 1 cytokine receptor activation motif [37]. However, none of the IL23R isoforms, including the full length form, was differential expressed in paratuberculosis. This is consistent with paratuberculosis in red deer [38], where IL23R showed no difference in expression in jejunal lymph nodes of animals with minimal (largely paucibacillary) or severe disease (multibacillary). Interestingly the ligand for the IL-23 receptor (IL-23A) is significantly increased in paucibacillary lesions but not in the draining lymph nodes [19]. In humans, the R318Q SNP protects against a number of immune-mediated diseases by reducing IL-23-mediated Th17 function [39]; this SNP was identified in the protein sequence translated from IL23R, IL23Rv1 and $v 4$ nucleotide sequences but no correlation with paratuberculosis pathology was identified.

All four IL12RB1 splice variants lack the WSXWS motif encoded within exon 7, suggesting that IL12RB1v1-v4 are non-functional or that they can act as modulators of IL-12/IL-23 activity by ligand binding without signalling. A truncated $I L 12 R B 1 \Delta t m$ variant lacking these domains has been identified in humans and mice [40]. In mice it is induced in dendritic cells (DC) after Mycobacterium tuberculosis infection [41]; expression promotes 
Table 3 Relative expression of cytokine receptor expression within the ICLN

\begin{tabular}{|c|c|c|c|c|c|c|c|}
\hline \multirow[t]{2}{*}{ Gene } & \multirow{2}{*}{$\begin{array}{l}\text { ANOVA } \\
p \text { value }\end{array}$} & \multicolumn{2}{|c|}{ Multi vs. control } & \multicolumn{2}{|c|}{ Pauci vs. control } & \multicolumn{2}{|c|}{ Multi vs. pauci } \\
\hline & & $\mathrm{FC}^{\mathrm{a}}$ & $p$ value & FC & $p$ value & FC & $p$ value \\
\hline IL23R & 0.501 & 0.6 & 0.97 & 1.35 & 0.54 & 0.98 & 0.99 \\
\hline $\mid L 12 R B 1$ & 0.232 & 0.97 & 0.99 & 1.57 & 0.28 & 0.62 & 0.28 \\
\hline IL12RB1V3 & 0.049 & 1.42 & 0.32 & -1.49 & 0.47 & 2.1 & 0.04 \\
\hline IL12RB1V4 & 0.079 & 1.1 & 0.89 & -1.72 & 0.18 & 1.87 & 0.08 \\
\hline IL17RA & 0.0016 & 0.46 & 0.43 & 2.2 & 0.02 & -2.0 & 0.001 \\
\hline$I L 17 R B$ & 0.035 & 2.49 & 0.04 & 1.19 & 0.93 & 2.08 & 0.08 \\
\hline IL 17RBV2 & 0.262 & 1.70 & 0.24 & 1.40 & 0.58 & 1.20 & 0.77 \\
\hline IL 17RBV3 & 0.104 & 1.60 & 0.12 & 1.52 & 0.24 & 1.09 & 0.88 \\
\hline
\end{tabular}

Italics $p \leq 0.05$.

a Fold change ( $\Delta \Delta$ Cq values).

DC migration and may act to up-regulate IL-12RB1dependent DC function and the immune response to mycobacteria. Mendelian susceptibility to mycobacterial diseases (immunodeficiency 30) can partly be explained by IL12RB1 deficiency; some of these patients express $5^{\prime}$-truncated IL12RB1 that encodes a non-functional protein incapable of binding IL-12 or IL-23 [42]. In the paratuberculosis studies only $I L 12 R B 1 v 3$ was differentially expressed with a significant increase in multibacillary vs. paucibacillary sheep. This variant contains the transmembrane and intracellular domains but is $5^{\prime}$ truncated and does not possess the WSXWS cytokine receptor activation motif. Like the $5^{\prime}$ truncated human variant it may bind the cytokines but not transduce the signal, possibly contributing to the low level of IL-12/IL-23 driven Th1/ Th17 activity associated with multibacillary/lepromatous pathology.

Only a single sheep $I L 17 R A$ transcript was identified. The predicted $5^{\prime}$ UTR of the sheep sequence shares $62.5 \%$ identity with the $5^{\prime}$ end of the human coding region (BC011624.2). Consequently the predicted sheep protein is only 249 amino acids rather than 866 amino acids of the full length human IL-17RA precursor (NP_055154.3). Two splice variants have been identified in humans, the full length transcript variant 1 (NM_014339.6) of 8607 bp and encoded by 13 exons and the soluble transcript variant 2 (NM_001289905.1) of 8506 bp without exon 11, which encodes the transmembrane domain [43]. However, no functional consequences have been associated with these variations. Sheep IL17RA includes exon 11 and expression is significantly higher in paucibacillary disease in comparison to both multibacillary and uninfected controls. IL-17RA is a component of the receptor (with IL-17RB) for both anti-inflammatory IL-25 and (with IL-17RC) the inflammatory Th17 cytokines IL-17A and IL-17F [44]; and high levels in paucibacillary animals could confirm a role of Th17 in paratuberculosis pathology [10].

The three splice variants of sheep $I L 17 R B$ are all predicted to encode truncated proteins. IL17RBv2 and $v 3$ encode identical short extracellular proteins that do not contain a transmembrane domain or intracellular region, it is therefore unlikely that they are cellular receptors but may bind and modulate IL-25 activity. The human truncated isoform 2 (Q9NRM) [45] has an unknown function and is produced at very low levels due to a premature stop codon in the mRNA, leading to nonsense-mediated mRNA decay. IL17RBv1 also encodes a truncated protein, with an amino-terminal truncated SEFIR (similar expression to fibroblast growth factor genes and IL-17R) domain and no TRAF6 binding motif. The SEFIR domain mediates protein interactions necessary for receptor signal transduction [46] and TRAF6 binding is essential for IL-25-mediated expression of IL-6 and TGF $\beta$ [47].

Only full length $I L 17 R B$ was differentially expressed in the paratuberculosis diseased sheep, expression in the ICLN of the multibacillary sheep was significantly greater (2.49-fold, $p=0.04)$ than in uninfected controls. The levels in paucibacillary and control animals were not significantly different. This argues that IL-25 signalling is playing a role in multibacillary (lepromatous) pathology. IL-25 interaction with IL-17RA/IL$17 \mathrm{RB}$ induces the production of the pro-inflammatory cytokines IL- 6 and IL- 8 by endothelia [48], and IL-4 and IL-13 by $\mathrm{T}$ cells [49] leading to the development of Th2-associated pathology [50] especially at mucosal sites.

In conclusion, we have identified transcript variants in sheep of the four genes that make up the receptor complexes of IL-23 and IL-25; two cytokines important for the development of Th1/Th17 and Th2 T cells and in the pathogenesis of inflammatory disease at mucosal 
surfaces. RT-qPCR analysis of the different variants highlighted the role of the amino-terminal truncated IL12RB1v3 and full length IL17RB in multibacillary pathology; and full length $I L 17 R A$ in paucibacillary disease. This study of the gene structure, sequence and expression of IL-23 and IL-25 has provided an initial insight into the role of differential $\mathrm{T}$ cell activation associated with the two pathological forms of sheep paratuberculosis.

\section{Additional files}

Additional file 1. Primer sequences used for amplifying full length genes. The primer sequences and their $\operatorname{Tm}\left({ }^{\circ} \mathrm{C}\right)$ used to amplify the full length cytokine genes; and PCR product size.

Additional file 2. Primer sequences used for RT-qPCR. The primer sequences and their $\mathrm{Tm}\left({ }^{\circ} \mathrm{C}\right)$ used to for relative RT-qPCR; and PCR product size.

\section{Additional file 3. Derived protein sequences of cytokine transcript} variants. A. IL-23R derived protein sequences. Comparison of IL $23 R$ and four transcript variants. B. IL-12RB1 derived protein sequences. Comparison of IL12RB1 and IL12RB1V3. C. IL-17RB derived protein sequences. Comparison of IL17RB and three transcript variants.

\section{Competing interests}

The authors declare that they have no competing interests.

\section{Author details}

${ }^{1}$ The Roslin Institute and R(D)SVS, University of Edinburgh, Easter Bush, Midlothian EH25 9RG, UK. ${ }^{2}$ Moredun Research Institute, International Research Centre, Pentlands Science Park, Penicuik, Midlothian EH26 OPZ, UK.

\section{Authors' contributions}

$\mathrm{JH}$ conceived the study, is the principal investigator and collected the negative control tissues. LN performed most of the experiments including gene cloning, RT-qPCR and the data analysis, and was supervised by JH and RD. AG performed the IS900 PCR. CW performed the post mortems and collected tissues from the diseased animals. FC performed the histopathology and was responsible for disease diagnosis. JH drafted the manuscript. All authors read and approved the final manuscript.

\section{Acknowledgements}

We acknowledge the pathology and clinical staff at the Moredun Research Institute. This project was funded by the Biotechnology and Biological Sciences Research Council (BBSRC) Institute Strategic Programme Grant to The Roslin Institute. LN is a BBSRC postgraduate student funded by the Doctoral Training Grant BB/D526245/1.

Received: 2 December 2015 Accepted: 26 January 2016

Published online: 09 February 2016

\section{References}

1. Harris N, Barletta R (2001) Mycobacterium avium subsp. paratuberculosis in veterinary medicine. Clin Microbiol Rev 14:489-512

2. Clarke C (1997) The pathology and pathogenesis of paratuberculosis in ruminants and other species. J Comp Pathol 116:217-261

3. Coussens P (2004) Model for immune responses to Mycobacterium avium subspecies paratuberculosis in cattle. Infect Immun 72:3089-3096

4. Perez V, Garcia Marin JF, Badiola JJ (1996) Description and classification of different types of lesion associated with natural paratuberculosis infection in sheep. J Comp Pathol 114:107-122
5. Dennis MM, Reddacliff LA, Whittington RJ (2011) Longitudinal study of clinicopathological features of Johne's disease in sheep naturally exposed to Mycobacterium avium subspecies paratuberculosis. Vet Pathol 48:565-575

6. Casanova J-L, Abel L (2002) Genetic dissection of immunity to mycobacteria: the human model. Annu Rev Immunol 20:581-620

7. O'Garra A, Redford PS, McNab FW, Bloom Cl, Wilkinson RJ, Berry MPR (2013) The immune response in tuberculosis. Annu Rev Immunol 31:475-527

8. Smeed JA, Watkins CA, Rhind SM, Hopkins J (2007) Differential cytokine gene expression profiles in the three pathological forms of sheep paratuberculosis. BMC Vet Res 3:18

9. Burrells C, Clarke CJ, Colston A, Kay JA, Porter J, Little D, Sharp JM (1998) A study of immunological responses of sheep clinically-affected with paratuberculosis (Johne's disease). The relationship of blood, mesenteric lymph node and intestinal lymphocyte responses to gross and microscopic pathology. Vet Immunol Immunopathol 66:343-358

10. Allen AJ, Park KT, Barrington GM, Lahmers KK, Abdellrazeq GS, Rihan HM, Sreevatsan S, Davies C, Hamilton MJ, Davis WC (2011) Experimental infection of a bovine model with human isolates of Mycobacterium avium subsp. paratuberculosis. Vet Immunol Immunopathol 141:258-266

11. Coussens PM, Pudrith C, Skovgaard K, Ren X, Suchyta S, Stabel J, Heegaard P (2005) Johne's disease in cattle is associated with enhanced expression of genes encoding IL-5, GATA-3, tissue inhibitors of matrix metalloproteinases 1 and 2, and factors promoting apoptosis in peripheral blood mononuclear cells. Vet Immunol Immunopathol 105:221-234

12. Chacon O, Bermudez LE, Barletta RG (2004) Johne's disease, inflammatory bowel disease and Mycobacterium paratuberculosis. Annu Rev Microbiol 58:329-363

13. van de Vosse E, Hoeve MA, Ottenhoff THM (2004) Human genetics of intracellular infectious diseases: molecular and cellular immunity against mycobacteria and salmonellae. Lancet Infect Dis 4:739-749

14. Saini C, Ramesh V, Nath I (2013) CD4 + Th17 cells discriminate clinical types and constitute a third subset of non Th1, Non Th2 T cells in human leprosy. PLoS Negl Trop Dis 7:e2338

15. Lees CW, Barrett JC, Parkes M, Satsangi J (2011) New IBD genetics: common pathways with other diseases. Gut 60:1739-1753

16. Van Limbergen J, Wilson DC, Satsangi J (2009) The genetics of Crohn's disease. Annu Rev Genomics Hum Genet 10:89-116

17. Kastelein RA, Hunter CA, Cua DJ (2007) Discovery and biology of IL-23 and IL-27: related but functionally distinct regulators of inflammation. Annu Rev Immunol 25:221-242

18. Zurbrick BG, Czuprynski CJ (1987) Ingestion and intracellular growth of Mycobacterium paratuberculosis within bovine blood monocytes and monocyte-derived macrophages. Infect Immun 55:1588-1593

19. Gossner AG, Venturina VM, Peers A, Watkins CA, Hopkins J (2012) Expression of sheep interleukin 23 (IL23A, alpha subunit p19) in two distinct gastrointestinal diseases. Vet Immunol Immunopathol 150:118-122

20. Khader SA, Cooper AM (2008) IL-23 and IL-17 in tuberculosis. Cytokine 41:79-83

21. Owyang AM, Zaph C, Wilson EH, Guild KJ, McClanahan T, Miller HR, Cua DJ, Goldschmidt M, Hunter CA, Kastelein RA, Artis D (2006) Interleukin 25 regulates type 2 cytokine-dependent immunity and limits chronic inflammation in the gastrointestinal tract. J Exp Med 203:843-849

22. Rickel EA, Siegel LA, Yoon BR, Rottman JB, Kugler DG, Swart DA, Anders PM, Tocker JE, Comeau MR, Budelsky AL (2008) Identification of functional roles for both IL-17RB and IL-17RA in mediating IL-25-induced activities. J Immunol 181:4299-4310

23. Abraham C, Cho JH (2009) IL-23 and autoimmunity: new insights into the pathogenesis of inflammatory bowel disease. Annu Rev Med 60:97-110

24. Morahan G, Kaur G, Singh M, Rapthap CC, Kumar N, Katoch K, Mehra NK, Huang D (2007) Association of variants in the IL12B gene with leprosy and tuberculosis. Tissue Antigens 69(Suppl 1):234-236

25. Elloumi-Zghal H, Barbouche MR, Chemli J, Béjaoui M, Harbi A, Snoussi N, Abdelhak S, Dellagi K (2002) Clinical and genetic heterogeneity of inherited autosomal recessive susceptibility to disseminated Mycobacterium bovis bacille calmette-guérin infection. J Infect Dis 185:1468-1475

26. Gallagher G, Yuv R, Kan S, Mancini G (2009) Splice variants of human IL-23 receptor (IL-23R) mRNA and use of a $\triangle 9$ isoform in predicting inflammatory bowel diseases. In: USPTO. Patent number 8206925 
27. Park JS, Park BL, Mo Kim, Heo JS, Jung JS, Bae DJ, Uh ST, Kim MK, Choi IS, Cho SH, Hong CS, Lee JY, Choi BW, Shin HD, Park CS (2013) Association of single nucleotide polymorphisms on Interleukin 17 receptor $A$ (IL17RA) gene with aspirin hypersensitivity in asthmatics. Hum Immunol 74:598-606

28. Jung JS, Park BL, Cheong HS, Bae JS, Kim JH, Chang HS, Rhim T, Park JS, Jang AS, Lee YM, Kim KU, Uh ST, Na JO, Kim YH, Park CS, Shin HD (2009) Association of IL-17RB gene polymorphism with asthma. Chest 135:1173-1180

29. McGhee JR, Fujihashi K (2012) Inside the mucosal immune system. PLoS Biol 10:e1001397

30. Eishi Y, Suga M, Ishige I, Kobayashi D, Yamada T, Takemura T, Takizawa T, Koike M, Kudoh S, Costabel U, Guzman J, Rizzato G, Gambacorta M, du Bois R, Nicholson AG, Sharma OP, Ando M (2002) Quantitative analysis of mycobacterial and propionibacterial DNA in lymph nodes of Japanese and European patients with sarcoidosis. J Clin Microbiol 40:198-204

31. Bauerfeind R, Benazzi S, Weiss R, Schliesser T, Willems H, Baljer G (1996) Molecular characterization of Mycobacterium paratuberculosis isolates from sheep, goats, and cattle by hybridization with a DNA probe to insertion element IS900. J Clin Microbiol 34:1617-1621

32. Sheep genome Assembly Oar v3.1 [online] http://www.livestockgenomics.csiro.au/sheep/oar3.1.php/

33. NCBI Primer BLAST [online] http://www.ncbi.n/m.nih.gov/tools/ primer-blast/

34. Primer, N., Net Primer [online] http://www.premierbiosoft.com/ netprimer/

35. The Ensembl Genome Browser [online] http://www.ensembl.org/

36. Kan SH, Mancini G, Gallagher G (2008) Identification and characterization of multiple splice forms of the human interleukin-23 receptor a chain in mitogen-activated leukocytes. Genes Immun 9:631-639

37. Dagil R, Knudsen MJ, Olsen JG, O'Shea C, Franzmann M, Goffin V, Teilum K, Breinholt J, Kragelund BB (2012) The WSXWS motif in cytokine receptors is a molecular switch involved in receptor activation: insight from structures of the prolactin receptor. Structure 20:270-282

38. Robinson MW, O'Brien R, Mackintosh CG, Clark RG, Griffin JFT (2011) Immunoregulatory cytokines are associated with protection from immunopathology following Mycobacterium avium subspecies paratuberculosis infection in red deer. Infect Immun 79:2089-2097

39. Di Meglio P, Di Cesare A, Laggner U, Chu CC, Napolitano L, Villanova F, Tosi I, Capon F, Trembath RC, Peris K, Nestle FO (2011) The IL23R R381Q gene variant protects against immune-mediated diseases by impairing IL-23-induced Th17 effector response in humans. PLoS One 6:e17160
40. van de Vosse E, Lichtenauer-Kaligis EG, van Dissel JT, Ottenhoff TH (2003) Genetic variations in the interleukin-12/interleukin-23 receptor (beta1) chain, and implications for $\mathrm{IL}-12$ and $\mathrm{IL}-23$ receptor structure and function. Immunogenetics 54:817-829

41. Robinson RT, Khader SA, Martino CA, Fountain JJ, Teixeira-Coelho M, Pearl JE, Smiley ST, Winslow GM, Woodland DL, Walter MJ, Conejo-Garcia JR, Gubler U, Cooper AM (2010) Mycobacterium tuberculosis infection induces il12rb1 splicing to generate a novel IL-12Rß1 isoform that enhances DC migration. J Exp Med 207:591-605

42. Fieschi C, Bosticardo M, de Beaucoudrey L, Boisson-Dupuis S, Feinberg J, Santos OF, Bustamante J, Levy J, Candotti F, Casanova JL (2004) A novel form of complete IL-12/IL-23 receptor b1 deficiency with cell surfaceexpressed nonfunctional receptors. Blood 104:2095-2101

43. Sohda M, Misumi Y, Tashiro K, Yamazaki M, Saku T, Oda K (2013) Identification of a soluble isoform of human IL-17RA generated by alternative splicing. Cytokine 64:642-645

44. Iwakura Y, Ishigame H, Saijo S, Nakae S (2011) Functional specialization of interleukin-17 family members. Immunity 34:149-162

45. Uniprot [online] http://www.uniprot.org/

46. Novatchkova M, Leibbrandt A, Werzowa J, Neubüser A, Eisenhaber F (2003) The STIR-domain superfamily in signal transduction, development and immunity. Trends Biochem Sci 28:226-229

47. Maezawa Y, Nakajima H, Suzuki K, Tamachi T, Ikeda K, Ji Inoue, Saito Y, I wamoto I (2006) Involvement of TNF receptor-associated factor 6 in IL-25 receptor signaling. J Immunol 176:1013-1018

48. Johansen C, Usher PA, Kjellerup RB, Lundsgaard D, Iversen L, Kragballe K (2009) Characterization of the interleukin-17 isoforms and receptors in lesional psoriatic skin. Brit J Dermatol 160:319-324

49. Saenz SA, Siracusa MC, Perrigoue JG, Spencer SP, Urban JF, Tocker JE, Budelsky AL, Kleinschek MA, Kastelein RA, Kambayashi T, Bhandoola A, Artis D (2010) IL25 elicits a multipotent progenitor cell population that promotes $\mathrm{T}(\mathrm{H}) 2$ cytokine responses. Nature 464:1362-1366

50. Fort MM, Cheung J, Yen D, Li J, Zurawski SM, Lo S, Menon S, Clifford T, Hunte B, Lesley R, Muchamuel T, Hurst SD, Zurawski G, Leach MW, Gorman DM, Rennick DM (2001) IL-25 induces IL-4, IL-5, and IL-13 and Th2-associated pathologies in vivo. Immunity 15:985-995

\section{Submit your next manuscript to BioMed Central and we will help you at every step:}

- We accept pre-submission inquiries

- Our selector tool helps you to find the most relevant journal

- We provide round the clock customer support

- Convenient online submission

- Thorough peer review

- Inclusion in PubMed and all major indexing services

- Maximum visibility for your research

Submit your manuscript at www.biomedcentral.com/submit

\section{( ) Biomed Central}

